\title{
Ricardo Arredondo (2012), Intervención humanitaria y Responsabilidad de Proteger ¿Hacia un nuevo paradigma de protección de los derechos humanos? (Buenos Aires: Catálogos). 384 pp.
}

\section{JORGE RIQUELME RIVERA}

Universidad de Chile

El tema de la intervención humanitaria formó parte importante de los debates de la comunidad internacional durante la década de los noventa, especialmente a partir de los sucesos de Kosovo y el bombardeo de la OTAN. En tal contexto, el año 2000 se creó, en el marco de Naciones Unidas, la Comisión Internacional sobre Intervención y Soberanía de los Estados (ICISS) , liderada por el ex Canciller australiano Gareth Evans y el ex Asesor Especial del Secretario General de Naciones Unidas para África, Mahmoud Sahnoun.

La ICISS cambió los términos del debate internacional, enfocándose ya no en el derecho a intervenir -que había predominado en las discusiones hasta ese momento-, sino en la responsabilidad de los Estados de proteger a las poblaciones amenazadas de desastres humanitarios. De este modo, el informe de la Comisión introdujo por primera vez el concepto de la Responsabilidad de Proteger (Responsibility to Protect), rearticulando el debate sobre la legalidad y la legitimidad de las intervenciones humanitarias (Orchard, 2012: 377).

Según la ICISS la Responsabilidad de Proteger representa una "norma emergente", que actúa como un concepto paraguas, que también involucra la responsabilidad de reaccionar, la responsabilidad de prevenir y la responsabilidad de reconstruir. Además, dispone que la comunidad internacional, mediante el Consejo de Seguridad, tiene la responsabilidad de actuar para proteger a las poblaciones amenazadas si el Estado es incapaz o se niega a hacerlo. De tal modo, para la ICISS la soberanía ya no se entiende como el ejercicio del poder soberano, sino como el respeto primordial del Estado a los derechos humanos.

Sobre esta base, en 2004 el Grupo de Alto Nivel de Naciones Unidas sobre Amenazas, Desafíos y Cambio endosó la noción de Responsabilidad de Proteger, la cual luego fue incorporada en el informe del Secretario General "Un concepto más amplio de la libertad" de 2005. En consideración a todo lo anterior, la Responsabilidad de Proteger fue adoptada por consenso en la Cumbre Mundial de 2005, en el marco de la Asamblea General de las Naciones Unidas (párrafos 138-139 del Documento Final) y reafirmada por el Consejo de Seguridad, en su resolución 1674 de 2006.

La Responsabilidad de Proteger representa un compromiso histórico de los Estados para proteger a las poblaciones de cuatro crímenes específicos: genocidio, depuración étnica, crímenes de guerra y crímenes de lesa humanidad, constituyéndose en una transformación 
fundamental respecto de las tradicionales concepciones acerca de la soberanía y su principio asociado de no intervención. Según este nuevo principio internacional, es obligación de los Estados proteger a sus ciudadanos ante tales crímenes y es deber de la comunidad internacional auxiliar a los Estados en el cumplimiento de esta tarea. No obstante, si el Estado no cumple con esta obligación, la responsabilidad recae sobre la comunidad internacional. Es decir, si el Estado afectado está incumpliendo con su obligación de proteger, y solo entonces, el Consejo de Seguridad podría considerar el uso de la fuerza. La Responsabilidad de Proteger se basa en tres pilares para su aplicación, a saber: 1) Advertencia, 2) Cooperación internacional para apoyar al Estado que no se encuentra en condiciones de proteger a su población y 3) Uso de la fuerza.

El tema de la Responsabilidad de Proteger, contrariamente a lo que sucede en Estados Unidos y Europa, no cuenta con una amplia literatura en América Latina y el Caribe. Sin duda, el libro del diplomático argentino Ricardo Arredondo viene a cubrir en parte esta carencia. ${ }^{1}$ En el texto, el autor realiza un extenso y profundo análisis jurídico y político de la Responsabilidad de Proteger desde sus orígenes en el informe de la ICISS, sin olvidar sus antecedentes previos en la conceptualización sobre la "soberanía como responsabilidad", del académico y diplomático africano Francis Deng, y la carta constitutiva de la Unión Africana.

Según Arredondo, actualmente existe en la política mundial una aguda tensión entre dos conceptos fundamentales que han estructurado hasta ahora las relaciones internacionales. Por una parte, la defensa de la autonomía de los Estados individualmente considerados de una interferencia exterior, lo que se asocia con el principio de la no intervención y, por otra, la preocupación por la protección de los derechos humanos de la población de un Estado en situación de violaciones graves de tales derechos y la provisión de medidas para poner fin o aliviar esta situación, lo que se conoce con el genérico de "intervención humanitaria" (p. 10). Esta tensión está en el centro del debate internacional sobre la naturaleza y aplicación de la Responsabilidad de Proteger.

El libro de Arredondo está estructurado en torno a cuatro partes, subdivididas en diez capítulos. La primera parte realiza una conceptualización de la intervención humanitaria, entendiéndola como una acción coercitiva emprendida por uno o varios Estados, o bien una organización internacional, que involucra el uso de la fuerza en otro Estado, sin la autorización del Consejo de Seguridad de Naciones Unidas y sin el consentimiento del Estado afectado, con el objeto de prevenir o poner fin a violaciones graves a los derechos humanos (p. 26).

Asimismo, en esta sección se analiza el desarrollo de la Responsabilidad de Proteger, considerando el cambiante significado de la soberanía en el escenario internacional, el ámbito de aplicación del mencionado concepto, así como su implementación.

1 En la misma línea, cabría destacar la reciente publicación del $N^{\circ} 35$ de la revista Pensamiento Propio, editada por el CRIES (Coordinadora Regional de Investigaciones Económicas y Sociales), dedicado a la Responsabilidad de Proteger y su aplicabilidad en América Latina. 
Por otro lado, los capítulos atinentes a la segunda parte realizan un acabado análisis del derecho internacional vigente en materia de intervención humanitaria y Responsabilidad de Proteger. En esta línea, el autor se refiere al tema de la prohibición de la amenaza y el uso de la fuerza en la Carta de Naciones Unidas; analiza la jurisprudencia de la Corte Internacional de Justicia (CIJ), deteniéndose en algunos casos relevantes, como el de Barcelona Traction y el canal de Corfú; y examina el funcionamiento de los mecanismos previstos por la Carta ante situaciones de crisis humanitarias. A este último respecto, Arredondo analiza el papel del Consejo de Seguridad, el rol subsidiario de la Asamblea General en materia de paz y seguridad internacionales y realiza una breve referencia a las actividades de organismos de naturaleza regional.

La tercera parte resulta particularmente interesante, por cuanto define distintas posiciones de países y grupos de países sobre la Responsabilidad de Proteger. En esta sección puede argumentarse que el análisis es fundamentalmente político y permite extraer la idea esencial de la falta de consenso entre los países acerca de dicho concepto. En esta línea se analizan las posiciones de los miembros permanentes del Consejo de Seguridad, los denominados P-5; las de los "candidatos" a miembros permanentes del Consejo (Alemania, Japón, India y Brasil, que forman parte del denominado G-4); así como las de otros Estados y agrupaciones de Estados, como la del Movimiento de Países No Alineados (NOAL), que se ha caracterizado por su reticencia y precaución ante la Responsabilidad de Proteger.

Como se aprecia meridianamente en este capítulo, pese a que el concepto de la Responsabilidad de Proteger fue aprobado formalmente por la comunidad internacional en la Cumbre Mundial de 2005, su contenido y su metodología no cuentan con un amplio consenso entre los países. Ciertos Estados en desarrollo agrupados, por ejemplo, en el NOAL, han expresado en numerosas ocasiones el temor de que la Responsabilidad de Proteger sirva como pretexto para la intervención, dañando las respectivas soberanías nacionales.

En esta sección también se analizan las posturas asumidas por los países en el contexto interamericano y latinoamericano. Según se aprecia, ciertos países, como es el caso de Chile, México, Colombia, Perú, Uruguay y El Salvador, sin dejar de defender el principio de no intervención, reconocen en la Responsabilidad de Proteger una oportunidad para la protección de los derechos humanos en casos de crisis humanitarias. Otros países, susceptibles de agrupar bajo el eje ALBA (Alianza Boliviariana para los Pueblos de Nuestra América), como Bolivia, Cuba, Ecuador, Nicaragua y Venezuela han sido particularmente críticos en torno al concepto, alegando que este podría justificar eventuales intervenciones extranjeras que atenten contra la soberanía de los países. También el autor califica a otros países como "eclécticos", es el caso de Argentina y Brasil, que, sin oponerse a la Responsabilidad de Proteger, han sido cautos frente al tema, poniéndose en una posición intermedia entre las dos posturas señaladas. A juicio de Arredondo, tales países estiman que el principio, sobre el cual albergan algunas dudas, necesita aún una mayor elaboración, particularmente en cuanto a la responsabilidad de reaccionar y el eventual uso de la fuerza (p. 266). 
En este punto cabe anotar que, seguramente por la fecha de edición del libro, Arredondo no se refiere a la nueva formulación planteada por Brasil sobre la "Responsabilidad al Proteger" (Responsibility While Protecting). De ser un actor cauto frente a la materia, el gigante sudamericano ha cobrado protagonismo a nivel regional al promover este concepto a partir de los sucesos de Libia, donde la resolución 1973 del Consejo de Seguridad, de marzo de 2011, tuvo como resultado no previsto en el mandato el cambio del régimen libio, materia que ha suscitado un amplio debate internacional.

La primera vez que la iniciativa brasileña apareció públicamente fue en un artículo del Canciller Antonio Patriota, publicado en el periódico Folha de São Paulo el 1 de septiembre de 2011. ${ }^{2}$ Una relación detallada de la noción propuesta por Brasil se encuentra en la Nota Conceptual Responsibility while Protecting: elements for the development and promotion of a concept, presentada mediante una carta por la Representante Permanente de Brasil ante las Naciones Unidas en Nueva York, Embajadora Maria Luisa Ribeiro Viotti, el 11 de noviembre de 2011. Según explica el documento, la iniciativa de Itamaraty no pretende sustituir a la Responsabilidad de Proteger, sino más bien complementarla mediante la creación de reglas más claras en los temas más polémicos, como otorgar el máximo de protección antes de tomar parte, máximo de cautela, y accountability ante el Consejo de Seguridad al intervenir. La propuesta de Brasil plantea que la aplicación de los pilares de la Responsabilidad de Proteger debe ser consecutiva, aplicándose primero la prevención y responsabilidad de los Estados, luego la cooperación internacional, para culminar con el tercer pilar relativo a las medidas coercitivas. ${ }^{3}$

La última parte del libro de Arredondo se refiere a la necesidad de alcanzar un nuevo consenso frente a la Responsabilidad de Proteger y al accionar del Consejo de Seguridad. En tal sentido, el diplomático argentino destaca los criterios de legitimidad para guiar la toma de decisiones del Consejo, propuestos por el Grupo de Alto Nivel de Naciones Unidas sobre Amenazas, Desafíos y Cambio: a) gravedad de la amenaza; b) propósito correcto; c) último recurso; d) proporcionalidad de los medios; e) balance de las consecuencias (p. 324). Estos criterios pretenden limitar y guiar la toma de decisiones de la comunidad internacional ante situaciones que requieran del uso de la fuerza.

Como se desprende de la obra de Arredondo, la necesidad de alcanzar un consenso internacional en materia de Responsabilidad de Proteger, resulta fundamental para avanzar en el resguardo de los derechos humanos, así como en la promoción de la estabilidad internacional. En último término, de ello depende una respuesta oportuna y eficaz de la comunidad de naciones ante situaciones de crisis donde se cometa genocidio, depuración étnica, crímenes de guerra y crímenes de lesa humanidad.

En las últimas páginas del libro, Arredondo se pregunta "¿Por qué debe preocuparnos el debate acerca de la Responsabilidad de Proteger?" a lo que responde: "Porque se trata de la expresión de una aspiración de poner en práctica una acción temprana y más

2 El texto se encuentra disponible en http://www1.folha.uol.com.br/fsp/opiniao/fz0109201107.htm Recuperado en diciembre de 2012.

3 Un riguroso análisis de la propuesta brasileña de la Responsabilidad de Proteger puede verse en Rodrigues (2012). 
eficaz para prevenir el agravamiento y la aparición de algunos de los peores delitos que cometen los seres humanos entre sí" (p. 346). Ello nos lleva a la conclusión de que, en última instancia, de la consolidación de la Responsabilidad de Proteger depende poner antídoto al unilateralismo y a la inacción del Consejo de Seguridad, ante los complejos desafíos de la realidad internacional contemporánea.

\section{REFERENCIAS}

Orchard, P. 2012. "The Evolution of the Responsibility to Protect: At a Crossroads?" International Affairs. Vol. 88, Issue 2: 377-386.

Rodrigues, G. 2012. “La responsabilidad al proteger: Motivaciones, contenidos y cambios”. Pensamiento Propio. No $35: 169-191$.

Jorge Riquelme Rivera. Magíster en Estudios Internacionales, Universidad de Chile. Doctorando en Relaciones Internacionales, Universidad Nacional de La Plata. Es analista político del Ministerio de Relaciones Exteriores de Chile y ejerce docencia en la Universidad de Chile.

E-mail: jlriquel@uc.cl 